\title{
The Line Manager's Role in Implementing Successful Organizational Interventions
}

\author{
Marit Christensen $^{1}$, Siw Tone Innstrand ${ }^{1}$, Per Øystein Saksvik ${ }^{1}$ and Karina Nielsen ${ }^{2}$ \\ ${ }^{1}$ The Norwegian University of Science and Technology (Norway) \\ 2 Sheffield University Management School (UK)
}

\begin{abstract}
The aim of the paper is to discuss the role of the line manager in implementing to plan, implement and evaluate successful organizational interventions using our experiences from the ARK-program. Earlier literature has shown that line managers have a major influence on an intervention's outcomes (Nielsen, 2017; Saksvik, Nytrø, Dahl-Jørgensen, \& Mikkelsen, 2002), however, there is a lack of knowledge about the managements' role throughout the entire intervention process and how line managers are influenced by the context at different levels. We therefore discuss the line managers' role within the five phase cycle of an organizational intervention, including preparation, screening, action planning, implementation and evaluation. We also introduce a more in-depth understanding of the context by using of the IGLOmodel (Individual, Group, Leadership and Organizational level). Based on our knowledge and experience from the ARK-program we make some recommendations for (a) what the line managers need throughout the five phases in order to contribute to a successful intervention, and (b) on what the line manager has to provide in order to develop and implement a successful intervention process.
\end{abstract}

Received 26 April 2018; Revised 26 November 2018; Accepted 10 December 2018

Keywords: evaluation, implementation, line managers, organizational interventions.

A healthy workplace is defined as a coexistence and integration between the organization's well-being (productivity and profit) and its employees' well-being (work engagement, health and performance) (Christensen, 2017; Kelloway, \& Day, 2005). Kelloway, Penney, and Dimoff (2017) suggest that the creation of a psychologically healthy workplace is closely connected to line managers' actions. Leadership is associated with many different employee outcomes, e.g. psychological wellbeing, stress, cardiovascular disease, and health related behavior (Kuoppala, Lamminpää, Liira, \& Vainio, 2008; Skakon, Nielsen, Borg, \& Guzmán, 2010). Leadership is a critical part of organizational interventions, both in terms of understanding the management's role throughout the process (Nielsen \& Randall, 2013; Saksvik, Olaniyan, Lysklett, Lien, \& Bjerke, 2015), as a contextual influence on intervention development and implementation (Biron \& Karanika-Murray, 2014). Studies have found that line managers have a major influence regarding an intervention's effects (Nielsen, 2017; Saksvik et al., 2002, 2018). In examining an organizational intervention that had failed, NytrØ, Saksvik, Mikkelsen, Bohle, and Quinlan (2000) found that the leader was the most important factor in explaining the failure. Westgaard and Winkel (2011) concluded

Correspondence concerning this article should be addressed to Marit Christensen. Norwegian University of Science and Technology (NTNU). Department of Psychology. Dragvoll. 7491 Trondheim (Norway).

E-mail: marit.christensen@ntnu.no in their review that key aspects involve the role of the leader, although there is limited specific awareness and knowledge of what that means in practice. In the present paper, we will emphasize the role of the line managers in implementing successful interventions.

There are several reasons for line managers being such an important factor for successful implementation of organizational interventions. Nielsen (2017) highlighted four:

1. The line managers function as the link between employees and senior management; they inform and discuss decisions made by senior management with their employees and then again feedback the reactions of their employees to senior management.

2 . They are responsible for converting senior management decisions into concrete actions and changes to work practices and procedures when developing and implementing interventions at work.

3. They have the main responsibility for prioritizing the intervention's actions and processes and ensure it is a continuous work.

4. They need to manage the employees' expectations about the interventions (Nielsen, 2017).

How to cite this article:

Christensen, M., Innstrand, S. T., Saksvik, P.Ø., \& Nielsen, K. (2018). The line manager's role in implementing successful organizational interventions. The Spanish Journal of Psychology, 21. e5. Doi:10.1017/SJP.2019.4 
Nielsen (2017) further suggested that leaders have the power to make or break an intervention, but at the same time asked the question if they really are the villains of the piece. She underlined the importance of the context, which may influence the leaders' ability to develop and implement successful organizational interventions. Nielsen, Randall, Holten, and Rial González (2010), presents a model of organizational interventions including five phases of an intervention cycle. The five phases include preparation, screening, action planning, implementation and evaluation. There is good reason to believe that the line manager is essential throughout all this phases. There is a lack of studies investigating in-depth how the line managers are influenced by the context throughout the five phases of the organizational intervention (Nielsen \& Noblet, 2018) and we would like to discuss our experiences with the ARK-program, which is built upon the five phases. The present study responds to the need of a more in-depth understanding on how the context influences the line manager during the intervention process. In order to contribute to a deeper understanding we will be looking at the context for the line managers at four different levels as presented in the IGLO-model (Day \& Nielsen, 2017; Nielsen et al., 2017). Across the five phases of the intervention process as suggested by Nielsen and colleagues (Nielsen \& Noblet, 2018; Nielsen et al., 2010), we will be using a comprehensive intervention program called the ARK-program as a case study.

\section{Theoretical background}

Nielsen and Miraglia (2017) suggest that a deeper understanding of the content and process mechanism of organizational interventions could help improve the outcomes related to employees' well-being and health, and that the context would decide if these mechanisms are triggered or not. Many of these contextual factors influence line managers' job during an intervention and affects whether it becomes a success or not (Nielsen, 2017). It is considered important to consider if the employees and the line managers have a shared view of their working environment and if necessary take action to adjust these discrepancies (Nielsen, 2017).

Participation of the employees is important in all of the intervention's phases is crucial (Nielsen et al., 2010), and it is the responsibility of the line manager to make sure that the employees are ready to change and participate in the whole process. The five phases are not orthogonal, but the model illustrates the complex processes of overlapping and interaction between the five phases (Nielsen \& Randall, 2013). The ARKprogram is built on, and all line managers follow, the five phases. To fully understand the context and mechanisms behind the intervention process all the five phases need to be implemented.

Previous literature has suggested a distinction concerning context during an intervention process; the omnibus context and the discrete context (Nielsen \& Abildgaard, 2013). The omnibus context concerns the characteristics of the organization, e.g. readiness for change, culture and climate, and can be examined on an individual, group and organizational level and the psychosocial work environment, while the discrete context is ongoing change during the intervention period like for example restructuring. Nielsen and Miraglia (2017) argue that we have to build upon our knowledge about the omnibus and discrete context and how it influences the line managers in order to plan for interventions. We would add contextual resources to this knowledge by using the framework of the IGLO-levels (Individual, Group, Leadership, Organization) (Day \& Nielsen, 2017; Nielsen et al., 2017). We argue that contextual resources at different levels within the working environment is important for the line manager to improve the employees wellbeing and the organizations' performance. First, resources at the individual level includes resources embedded in the personal characteristics of the line manager like e.g. motivation, competence skills, selfefficacy. The second level includes group level resources within the social context of the workplace. At this level there is room for exchanging information and experiences with colleagues, including social support knowledge exchange and followership between line managers and with co-workers. Third, the leader level resources, in our case this will deal with the senior managements' impact on line managers including e.g. social support, motivation, communication and acknowledgement. The last level is the organizational level, which are the resources embedded in the way the work is organized, designed and managed, which in this case includes HR, consultancy firms, and the ARK-program's support functions. This might include for example training programs, project management and cultural understanding.

Through the development of a more in-depth understanding of the context and mechanisms that influence how the line manager manages the intervention throughout the five phases, we can make some recommendations for organizations in their work on improving the psychosocial work environment and employee health and well-being. The recommendations are based on our experience from participating in developing and planning the ARK-program, and continuously conducting research on the ARK-program since 2011. Based on the Knowledge Intensive Work Environment Target data (KIWEST data), quantitative research has been conducted on relationship of importance for 
faculty staff psychosocial work environment and outcomes, as well as possible differences across gender, age and occupational positions within the academia. In addition, qualitative interviews have been conducted on line managers' role in the ARK-program. This research based knowledge is continuously back translated into best practice to inform and improve future implementation and development of interventions in the ARK program. We also presented these research results on a learning and experience conference which is arranged annually for practitioners, researchers and persons in lead of the ARK program.

\section{The ARK-program}

ARK is a comprehensive research based plan and tool for (a) systematic mapping of the psychosocial work environment, and (b) development and implementation of interventions for improving well-being, health and performance in higher education in Norway (Innstrand, Christensen, Undebakke, \& Svarva, 2015). The objective of having a common tool for all universities and university colleges in Norway was to have a research-based understanding of the development and consequences of potential changes of the psychosocial work environment in academia in Norway. Another aim was to have an instrument that was sector specific to detect the particular characteristics and challenges of the academic sector. In order to achieve a common platform and a national baseline, a common databank was established based on data from 18 institutions and over 15,000 respondents).

The ARK-program consists of the KIWEST Questionnaire with 29 standardized validated measures on job demands, resources, climate, motivational and health-related outcomes (Innstrand et al., 2015). KIWEST is based on the Job Demand-Resources (JD-R) model (Bakker \& Demerouti, 2007, 2014). The questionnaire includes scales that reflect the central variables from the model. This flexible model consists of two underlying psychological processes, a health impairment process and a motivational process (Bakker \& Demerouti, 2007; 2014). The model postulates that both the motivational process and the health impairment process are independent of which specific demands and recourses we use in the model, indicating that we can use the model across different contexts (Bakker \& Demerouti, 2007). The model can be used to predict burnout and work engagement, and consequently employee well-being, health and performance.

Further, ARK contains two types of fact sheets questionnaires which are to be completed by the line managers at each department together with the personnel safety representative to ensure cooperation between the parties. Fact Sheet I is supposed to be measuring facts about the organizational and structural conditions that might influence the work environment of the institutions. Fact Sheet II contains questions regarding evaluation of the work environment survey. The ARKprogram also presents a guide for the survey feedback meeting including a template for presentations, meetings and processes. Finally, it includes a database - the ARK research platform at HUNT which is a collection of data from all surveys conducted within the ARKprogram. All researchers can apply for using these data ${ }^{1}$.

\section{The line managers' role and context in the implementation of ARK}

Good leadership is considered to be one of the most crucial success factors in an organizational intervention, and it is important throughout all the five suggested phases of an intervention (Nielsen \& Noblet, 2018). In the remainder of the paper, we discuss and provide recommendations based on from our experiences with the ARK-program. First, we discuss what the line managers need throughout the five phases in order to manage a successful intervention, and second, we discuss what the line manager need to do to ensure a successful intervention process. We use the IGLOmodel (Nielsen et al., 2017) to gain insight in how the context in different levels affects the line managers' role throughout the five phases of the intervention.

\section{The initiation phase}

At the individual level, our experiences show that one important success factor is the line manager's understanding of the process. This understanding is important to ensure the necessary motivation and engagement for the intervention process. To achieve this, the anchoring process and training is essential (Nielsen et al., 2010). In the ARK-program, line managers are recommended to get to know the process and the possibilities within the tool, which means that they have to learn how to use the content of the different templates of the instrument and adjust it to their context with their unique possibilities and challenges. To achieve this understanding, line managers are offered an extensive training program during the initiation phase (see below under organizational resources for a detailed description). The initiation phase in the ARK-process at each university lasts about six months in order to anchor, train and motivate line managers and their employees to understand the process and be ready for change. This time is important in order to develop the line manager's self-efficacy through training so they

\footnotetext{
${ }^{1}$ The link to the database can be found here: https:/ / hunt-db.medisin. ntnu.no/ark/\#home
} 
feel capable of managing the process and address the challenges that might come up throughout the entire process. Training are shown to provide leaders with such resources in supportive work environments (Nielsen \& Daniels, 2012; Nielsen, Randall, \& Christensen, 2010). Still there are some challenges regarding the line managers' previous experiences regarding work environments surveys and their achievements and outcomes. The line managers' mental models are important in this phase because they need to communicate their own engagement and motivation for doing the ARKintervention to their employees. If the line managers believe in the ARK-program and have had positive previous experiences with it, their positive attitude and motivation will be more likely visible both in the initiation phase where they prepare and communicate the rationale behind the program to their employees and motivate them to participate actively. Further, they are more likely to put effort in preparing for the survey feedback meeting and work actively on the implementation of actions. The ARK-program demands a lot of effort and ongoing hard work from the line managers in order to succeed with promoting a positive psychosocial work environment. Therefore, in order to achieve this, the line managers need to believe in the program and be motivated and engaged in the work.

At the group level, the line manager needs the employees to be ready for change and participate actively in the intervention. Co-workership (Schrøder, Christensen, Innstrand, \& Fjeld, 2017) is key at this level, where the line manager needs the employees to ask themselves: What can I do for my workplace in order to improve the environment for myself and my colleagues, contribute to making my line manager good and create growth in the organization?" Employees should not just ask for what the line manager can do for them and their work environment; it is a co-creation process. Nielsen and Randall (2012) argue that both line managers and employees should have a shared picture of the goals is important to achieve a successful intervention outcome. In order to make an intervention work, both the line manager and the employees need to have positive attitudes towards it. Nielsen (2017) refers to social identity theory in order to explain this association. The more the line manager and the employees share perceptions, the more likely they are to succeed with the intervention. The line manager and the department's safety representative fill in Fact Sheet I (information about the organizational structures) together in order to get a common platform and understanding of the process and the current situation. Hasson et al. (2016) found that when the line manager and the employees shared a perception of a good learning climate, the experience of improvement in the working environment was believed to be better.
Where the leaders and employees have a shared perception of the intervention as something useful and clearly see how they can contribute towards making it successful, they would be more likely to toward together on implementing the intervention (Nielsen \& Daniels, 2012). A progress plan and a communication plan are recommended for implementing the ARKprogram as in line with Nielsen et al. (2010). Depending on the size and complexity having steering group with representatives from the employer and the employees is recommended (Undebakke, Innstrand, Anthun, \& Christensen, 2014). The management is encouraged to choose representatives whom they can trust and have an open dialogue with.

At the leadership level, line managers depend on support from senior management, and that the intervention as a whole is solidly anchored within the priorities of senior management. Several studies underline the importance of good anchoring of the project in senior management and among the line managers and readiness for change, as well as clear goal setting, good communication routines and well defined action plans (Aust, Rugulies, Finken, \& Jensen, 2010; Nielsen et al., 2010). It is recommended that managers at all levels in the institution are familiar with the ARK-program, and it should be presented and discussed in managerial meetings at all levels of the organization where also employee representatives are present. The ARKprogram offers training to all senior managers and line managers in the first phase. The senior management is important to line manager as the driver of change by functioning as role models or by assuming responsibility for developing and implementing the intervention (Nielsen, 2017). The senior management's motivation and confidence in the ARK-program seems to be of great importance in motivating, acknowledging, promoting, and communicating the importance of participating in the program to the line managers and the employees. For example, In the ARK-program some faculties have had with great success with "homemade" promotion videos encouraging participation in the ARK-program². Examples like this have in several cases helped ensure a good response rate, probably due to the fact that senior managers clearly demonstrate their belief in the ARK-program, that they are ready to spend time and energy on the program and that they are willing to implement changes.

At the organizational level, training is important. The training is recommended to all the leaders at all levels of the organizations. The ARK-program offers training in both the theoretical framework, but also in the practical management of the whole process. The ARK-program also offers a template that the line

\footnotetext{
${ }^{2}$ https:/ / www.youtube.com/watch?v=ilcJ4o0ohQA
} 
managers can use for informing the employees on the rationale behind ARK and some recommendations on how to motivate employees. Line managers may often find it difficult to present the theoretical background for their employees without the necessary background and the ARK-program has therefore made a video showing the rationale behind the JD-R model ${ }^{3}$. In the academic setting, employees are interested and motivated by an intervention with a solid theoretical and research-based foundation. The theoretical foundation based on the JD-R-model (Bakker \& Demerouti, 2007, 2104) together with research from the common databank seems to be an important background for line managers to use in order to motivate, create understanding, anchor and legitimate the ARK-process among their employees. Strong leadership support is recommended for line managers and help to facilitate the processes before and during the survey feedback meeting and with the implementation of interventions (Ipsen, Gish, \& Poulsen, 2015).

\section{The screening phase}

In the second phase, screening, the KIWEST questionnaire is a significant ingredient. KIWEST is built upon the JD-R model (Bakker \& Demerouti, 2007, 2014) including both measures for job resources and job demands. Participation and response rate are important factors in this phase and the line managers play a significant role in that matter. At the individual level, the line manager need to use his or her communication and project management skills in order to motivate and engage their employees in answering the questionnaire. At the group level, feedback from the line managers is that the quality of the questionnaire is important. The psychometric properties of KIWEST have been showed to be valid and reliable (Innstrand et al., 2015). The thorough theoretical and methodological background applies to and motivates the employees in universities and leads to higher participation and trust towards the ARK-program which is useful for the line manager. The continuous support from senior management, the HR-administration and the ARKrepresentatives in recruiting respondents for replying to the survey is still crucial for the response rate and a prerequisite for a successful intervention process.

\section{The feedback and action planning phase}

In Phase 3, the results from the KIWEST survey are presented in survey feedback meetings, preferably by the line manager or process leaders. In this setting the process leaders could be chosen from the

3https: / / www.youtube.com/watch?v=7SpNwY7gobU\&index=2\& list=PLUHTGp7T4Zn8yPeDpg2cba64KOPlahKzH
HR-administration or a consultancy firm. In these meetings, results of the survey are interpreted and discussed by employees, and suggestions for suitable actions for improving the psychosocial work environment are discussed in groups and presented in plenum for all the employees after the group work is final.

At the individual level, the line managers' personal characteristics are important. Line managers need to be open-minded, analytical, listening and empowering and emphatic. Survey results can sometimes be hard to both accept and present for the line manager, but they need to keep the professionalism throughout the feedback. At the group level, employees need to be ready to change, show followership and actively participate in the survey feedback meeting. The research-based foundation creates a legitimacy of the ARK-program, which is useful for the line managers in the anchoring process with their employees. Furthermore, research on the psychosocial work environment and well-being, health and performance conducted on the university sector, showing which psychosocial factors that are important for the academic work environment, together with a research-based understanding of how the processes behind influences the outcome of the intervention is helpful for the line managers in creating a best practice model in the future. The survey feedback process and development of areas to improve and preserve is bottom-up based. Employees work individually and in groups with identifying three areas they are satisfied with and would like to preserve, and three areas that can be improved. The groups meet at the end in a plenary session. After prioritizing these different needs for action employees are tasked with developing appropriate actions that address the problems identified in the survey. In order to achieve this, employees need to be motivated show followership and actively participate in the work. They need to be ready to change. The line manager is finally responsible for outlining how the future work on developing actions and implementing them should continue. This is a critical point of departure because all line managers have the freedom to choose which approach and methods the line managers want to use for their department or unit. At the leadership level, senior management need to be willing to allocate the necessary resources and support, time and space to plan, arrange and work with the survey feedback meeting, both in advance and after. At the organizational level, it is recommended that the work with the ARK-intervention is included in the university level policy and in strategic documents. The ARK-program does not offer any templates or tools for neither development of interventions nor implementation of interventions. The line manager's freedom to choose has been the essential idea behind this choice, however, our experiences 
underline the need for more tools and support in this and the following phase.

\section{The implementation phase}

In Phase 4, ARK recommends that the line manager should prioritize the interventions, deadlines should be set and both the plans and the progress should be fed back to the employees and discussed in regular meetings for all the employees. At the individual level, it is critical that the line manager has an overview, pushes the implementation of actions and possess systemic skills, i.e. understand that if one aspect of the work environment changes, this is likely to influence other parts of the work environment. Line managers also need the employees at the group level to engage in knowledge exchange, to support the process and implementation, be proactive, take responsibility, show followership, accept actions and follow them through. Line managers need resources, time, guidance, and support from senior management at the leadership level.

At the organizational level, it is our experience that it can be challenging to translate findings from the survey into concrete actions. At good starting point is to look at results from the ARK databank to make the process of going from feedback on abstract psychological concepts to concrete actions to improve the psychosocial work environment easier. Some examples of studies based on ARK-data are for example what factors motivate performance related to both teaching and research (Christensen, Dyrstad, \& Innstrand, 2016). Another study has investigated how the work-family balance is perceived by academics, and which factors that influence the balance (Listau, Christensen, \& Innstrand, 2017). We have also conducted several studies on the intervention processes in ARK, one conducting a process evaluation of an intervention process at one university department (Saksvik et al., 2015) and one effect evaluation of the same intervention (Saksvik et al., 2018) followed by a paper on leadership (Christensen \& Saksvik, 2018). To further ease this process we suggest that a tool is needed to help the line manager and the employees transforming abstract results from psychological constructs in the questionnaire into concrete actions. Such a tool would help the line manager and the others involved in analyzing the process asking questions on how does it look like, how do you perceive it, what ideas do we have and what do we do. This tool could contribute to clearer goal setting and evaluation of anticipated consequences of the interventions, to prioritize, think about who is responsible and how should the follow-up process go and how should the interventions be evaluated.

\section{The evaluation phase}

In Phase 5, the Fact Sheet II is distributed to all line managers of units that have had gone through the ARK-process. Fact Sheet II is completed by the line manager in collaboration with the safety representative and offers a self-evaluation of the process and interventions completed in the ARK-program. At the individual level, the line manager needs to possess skills that relate to being critical, open-minded and analytical. Listening skills are particularly important in the meeting with the safety representative. At the group level, the line manager need employees to be willing to engage dialogue directly or through their safety representative, give support and be willing to take time and share experiences throughout the intervention process.

The ARK-program states that both the process itself and its effect should be evaluated, however, there are some challenges regarding this phase, and for getting the answers needed for shedding light on what work for whom under which circumstances, and why more work is needed (Undebakke et al., 2014). First, regarding the effect evaluation, the KIWEST-questionnaire is measured every second or third year, making it possible for the line manager to compare the results from time to time to see whether there have been any improvements or not. The randomized controlled trial (RCT) is the most widely used standard for evaluating organizational interventions (Richardson \& Rothstein, 2008). This approach has been concluded to be inadequate because of its linear causations (Nielsen \& Miraglia, 2017; Nielsen \& Randall, 2013). The challenge is that in an organization, there are so many things going on at the same time making it problematic to conduct RCTbased evaluations. This means that in addition to the effect evaluation, process evaluation is needed for the line manager to fully understand what has been the result of the intervention and how the process has influenced the outcomes of the intervention, i.e. its ability to improve the work environment and employee well-being. Just knowing whether the intervention worked or not is insufficient to make changes to the process when the next cycle is begun (Nielsen \& Miraglia, 2017). Line managers need to understand what worked for whom in which circumstances in order to improve the intervention and engage in organizational learning (Nielsen, 2013; Nielsen \& Abildgaard, 2013; Nielsen \& Miraglia, 2017). The ARKprogram suggests that the process evaluation should ideally start already at the anchoring phase (Undebakke et al., 2014). All phases interact with each other and to fully understand what is going on and why it is going on, line manager need to evaluate the whole process together with their employees. Interviews and focus 
group interviews are useful to understand the process. After the first cycle of the five phases has been completed, line managers fill in Fact Sheet I again, however, the next time around the Fact Sheet questionnaire is expanded to include questions regarding which actions were implemented and how it went and how satisfied they were with the overall intervention process. Evaluation is an important part of the ARK-program, however the tools for evaluation of the process still has some weaknesses which should be looked deeper into. One suggestion could be to develop a more process oriented tool for the line managers to continuously evaluate the ongoing process throughout the five phases supporting the line managers' opportunity to make changes and keep up momentum. The ARK process is repeated at regular intervals of two or three years, and the work with the psychosocial work environment should be systematic and ongoing the entire time. An overview of the recommendations for what the line managers need in order to promote a successful intervention is given in Table 1.

The importance of working systematically and continuously with implementing interventions for improving the psychosocial work environment and employees' health and well-being. This underlines the importance of developing learning capabilities in the organization. An annual conference for exchange of experience between the process leaders and those who are working with ARK has been held in 2015, 2016 and 2017 with different topics on the agenda. The topics are based on feedback on challenges from the process leaders. The first conference was on communication of results, the second on strategic and long term thinking and good interventions. The last one was on perpetuity from the management perspective. These conferences have around 100 participants and they are strongly oriented towards group work on relevant topics put forward by themselves based on perceived needs and exchange of experiences from their university or university college.

Having discussed what the line managers need from the context in order to develop and implement a successful intervention brings us to another question; what does the line managers has to provide in order to contribute to a successful intervention process?

\section{What does the line manager need to do?}

In the initiation phase, experiences from the ARKprogram underlines that the line manager needs to communicate the vision of the process to the employees, the content of it, give feedback from the actions and results of previous interventions, further they need to identify the drivers of change among the employees, outline planning of the entire process, and acknowledge time and space. In order to manage this, the line manager's mental model needs to be positive towards the interventions process and act as a change agent (van den Heuvel, Demerouti, \& Bakker, 2014). Risk assessment is also recommended to be carried out to see whether the units have any special challenges such as conflict, low scores on line manager assessment, language barriers and so on in line with Nielsen and Randall (2012). Finally, line managers need to make the employees understand the need for participation and contribution throughout all the phases of the intervention. The line manager carries the main responsibility for the intervention throughout all phases.

In the survey phase, the line manager need to continuously follow up and communicate about the response rate during the survey in order to secure a high response rate and participation. It has been found that intervention participation has improved when line managers was supportive of the program (Coyle-Shapiro, 1999). Sørensen and Holman (2014) found that successful interventions had line managers who worked to make the intervention clear and visible for their employees.

In the action planning phase, the line manager needs to empower employees to engage in the bottom-up process. They need to facilitate the dialogue and discussion throughout the survey feedback meeting and communicate accountability of the employees in shaping the actions (co-workership). It is important that the line manager takes the lead in facilitating the translations of the results into feasible and sustainable actions. Further, they need to communicate future work action planning in ensuring detailed action plans who does what, why do they do it, and when?

In the implementation phase, the line manager should create a dialogue with their employees about the progress. He or she should prioritize the actions and make resources available to make changes. At this time, it is also important to engage in an ongoing dialogue with the senior management. Throughout this phase it could be a good idea to have small minievaluations to see what works or not so the course could be changed, minor corrections cold be done and actions not working could be stopped and replaced with other more constructive actions.

In the last phase, the evaluation phase the line manger need to work on identifying what worked for whom under which conditions, and why. Further he or she need to transfer this knowledge and experiences and communicating the results to the employees. Table 2 gives an overview of the recommendations for what the line managers should provide in a successful intervention process.

The line manager is important and crucial for successful interventions in all the five phases. Line managers can make or break and intervention, but they 
Table 1. What the Line Managers need

\begin{tabular}{|c|c|c|c|c|c|}
\hline & Phase1: Initiation & Phase 2: Survey & $\begin{array}{l}\text { Phase3: Survey feedback/ } \\
\text { development of interventions }\end{array}$ & $\begin{array}{l}\text { Phase 4: Implementation } \\
\text { of interventions }\end{array}$ & $\begin{array}{l}\text { Phase 5: Evaluation of } \\
\text { interventions }\end{array}$ \\
\hline $\begin{array}{l}\text { I - individual } \\
\text { resources }\end{array}$ & $\begin{array}{l}\text { - Self-efficacy } \\
\text { - Motivation/ engagement } \\
\text { - Understanding of the process } \\
\text { - Previous experience } \\
\text { - Internalization } \\
\text { - Communication skills } \\
\text { - Project management skills } \\
\text { - To be proactive- participate in } \\
\text { knowledge exchange, obtain knowledge }\end{array}$ & $\begin{array}{l}\text { - Communication } \\
\text { skills } \\
\text { - Project management } \\
\text { skills } \\
\text { - Motivation/ } \\
\text { engagement } \\
\text { - Creative (videos), } \\
\text { persuasive }\end{array}$ & $\begin{array}{l}\text { - Communication skills } \\
\text { - Project management skills } \\
\text { - Motivation/engagement } \\
\text { - Open-minded } \\
\text { - Being analytical } \\
\text { - Empowering/ emphatic } \\
\text { - Being professional, } \\
\text { - Listening skills }\end{array}$ & $\begin{array}{l}\text { - Communication skills } \\
\text { - Project management skills } \\
\text { - Motivation/ engagement } \\
\text { - Have an overview, } \\
\text { structured } \\
\text { - Push thing forward } \\
\text { - Systemic skills, if you } \\
\text { change one thing how does } \\
\text { that influence the system }\end{array}$ & $\begin{array}{l}\text { - Communication skills } \\
\text { - Project management skills } \\
\text { - Motivation/ engagement } \\
\text { - Being critical analytical } \\
\text { - Listening skills } \\
\text { - Open-minded }\end{array}$ \\
\hline G - group level & $\begin{array}{l}\text { - Exchange of experience and knowledge } \\
\text { - Knowledge exchange - formal and } \\
\text { informal } \\
\text { - Support - emotional and instrumental } \\
\text { - Participation } \\
\text { - Buy in } \\
\text { - Followership } \\
\text { - Ready for change }\end{array}$ & $\begin{array}{l}\text { - Knowledge exchange } \\
\text { for increasing the } \\
\text { response rate } \\
\text { - Participation } \\
\text { - Encourage colleagues } \\
\text { to participate }\end{array}$ & $\begin{array}{l}\text { - Buy in } \\
\text { - Followership } \\
\text { - Knowledge exchange for } \\
\text { increasing the response rate } \\
\text { - Participation } \\
\text { - Encourage colleagues to participate } \\
\text { - Participation } \\
\text { - Buy in } \\
\text { - Followership } \\
\text { - Ready for change } \\
\text { - Cooperation between colleagues }\end{array}$ & $\begin{array}{l}\text { - Knowledge exchange } \\
\text { - Support from staff, being } \\
\text { proactive, taking } \\
\text { responsibility, followership, } \\
\text { accepting the ideas and } \\
\text { following them through } \\
\text { - Employees Supporting the } \\
\text { process }\end{array}$ & $\begin{array}{l}\text { - Staff willing to engage } \\
\text { dialogue through their } \\
\text { safety representative, } \\
\text { support } \\
\text { - Cooperation with safety } \\
\text { representative } \\
\text { - Employees willing to } \\
\text { take time and share } \\
\text { experience }\end{array}$ \\
\hline L - leader level & $\begin{array}{l}\text { Motivation, acknowledge and } \\
\text { promote, communicate the } \\
\text { importance, integration to formal } \\
\text { documentation }\end{array}$ & $\begin{array}{l}\text { - Support from senior } \\
\text { management }\end{array}$ & $\begin{array}{l}\text { - Time and space } \\
\text { - Allocate resources } \\
\text { - Being present }\end{array}$ & $\begin{array}{l}\text { - Time and space } \\
\text { - Motivation and prioritization } \\
\text { - Active engagement, more } \\
\text { involvement, follow-up, } \\
\text { - Allocate resources } \\
\text { - Good role model }\end{array}$ & $\begin{array}{l}\text { - Make the adequate } \\
\text { changes and integrate } \\
\text { learning. } \\
\text { - Understand and motivate } \\
\text { process evaluation } \\
\text { - Support }\end{array}$ \\
\hline $\begin{array}{l}\mathrm{O} \text { - organizational } \\
\text { level }\end{array}$ & $\begin{array}{l}\text { - Training } \\
\text { - Templates } \\
\text { - Cultural understanding } \\
\text { - Project management } \\
\text { - Advisory board } \\
\text { - Sounding board }\end{array}$ & $\begin{array}{l}\text { - Follow-up } \\
\text { response rate } \\
\text { - Data management }\end{array}$ & $\begin{array}{l}\text { - Interpretation of results and } \\
\text { a risk analysis } \\
\text { - Template/video } \\
\text { - Tool } \\
\text { - Leader support, back-up } \\
\text { - Participation } \\
\text { - Sounding board/ reference } \\
\text { group/ sparringspartner } \\
\text { - Time and space } \\
\text { - Allocate resources } \\
\text { - Included in the university level } \\
\text { policy - strategic documents }\end{array}$ & $\begin{array}{l}\text { - Tool/template/ } \\
\text { questionnaire } \\
\text { - Allocate resources } \\
\text { - Project management } \\
\text { - Sounding board }\end{array}$ & $\begin{array}{l}\text { - Tool } \\
\text { - Allocate resources } \\
\text { - Sounding board }\end{array}$ \\
\hline
\end{tabular}




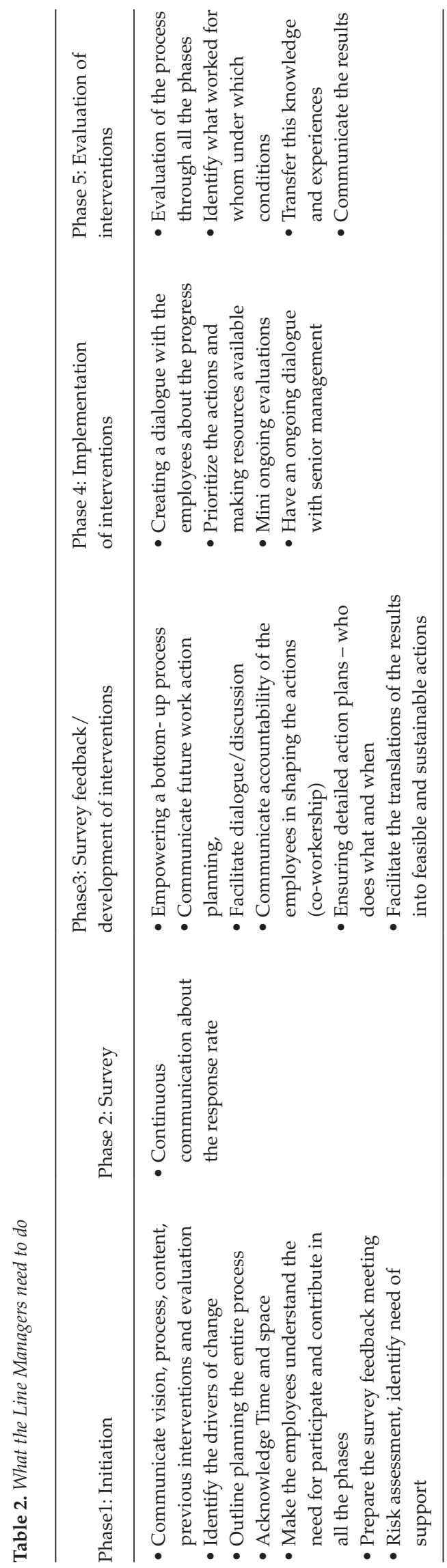

might not always be the villains of the piece. Context plays an important role, and resources at all four level: The leader's own personal resources, the resources inherent within the work group they are responsible for or their peers, the support of senior management and the organizational context all play an important role in supporting the line manager in implementing successful interventions. In order to succeed in implementing interventions with good results the line manager needs a constructive and supportive context. To fully understanding how the context influences the line managers throughout the intervention process we recommend further research to look deeper into all the levels of the organization. A more in-depth understanding of how the context influences the line managers' mental models and actions will make it easier to develop the most constructive framework regarding training, tools and support systems for the line manager in the intervention process.

\section{References}

Aust B., Rugulies R., Finken A., \& Jensen C. (2010). When workplace interventions lead to negative effects: Learning from failures. Scandinavian Journal of Public Health, 38, 106-119. https://doi.org/10.1177/1403494809354362

Bakker A. B., \& Demerouti E. (2007). The Job DemandsResources model: State of the art. Journal of Managerial Psychology, 22(3) 309-328. https://doi.org/10.1108/ 02683940710733115

Bakker A. B., \& Demerouti E. (2014). Job DemandsResources Theory. In P. Y. Chen \& C. L. Cooper (Eds.), Work and wellbeing. Wellbeing: A complete reference guide (Vol. III, pp. 37-64). Chichester, UK: Wiley-Blackwell.

Biron C., \& Karanika-Murray M. (2014). Process evaluation for organizational stress and well-being interventions: Implications for theory, method, and practice. International Journal of Stress Management, 21, 85-111. https:/ / doi.org/ $10.1037 / a 0033227$

Christensen M. \& Saksvik P. Ø. (2018, September). How to succeed with an occupational health intervention Lessions learned from a five year project. Paper presented at Conference of the European Academy of Occupational Health Psychology. Lisbon, Portugal. Retrieved from http:/ / www. eaohp.org/uploads/1/1/0/2/11022736/2018_book_of_ proceedings.pdf

Christensen M. (2017). Healthy individuals in healthy organizations: The Happy Productive Worker Hypothesis. In M. Christensen, P. Ø. Saksvik, \& M. Karanika-Murray (Eds.), The positive side of occupational health psychology (pp. 155-169). Cham, Switzerland: Springer.

Christensen M., Dyrstad J. M., \& Innstrand S. T. (2016). Academic work engagement, resources and productivity: implications for intervention policies. Retrieved from http:/ / www.srhe.ac.uk/conference2016/abstracts/0184.pdf

Coyle-Shapiro J. A.-M. (1999). Employee participation and assessment of an organizational change intervention. A three-wave study of total quality management. The Journal 
of Applied Behavioral Science, 35(4), 439-456. https: / /doi. org $/ 10.1177 / 0021886399354006$

Day A., \& Nielsen K. (2017). What does our organization do to help our well-being? Creating healthy workplaces and workers. In N. Chmiel, F. Fraccoli, \& M. Sverke (Eds.), An introduction to work and organizational psychology: An international perspective (p. 295). Sussex, UK: Wiley Blackwell.

Hasson H., von Thiele Schwarz U., Nielsen K., and Tafvelin S. (2016). Are we all in the same boat? The role of perceptual distance in organizational health interventions. Stress and Health, 32(4) 294-303. https:/ /doi.org/10.1002/ smi.2703.

Innstrand S. T., Christensen M., Undebakke K. G., \& Svarva K. (2015). The presentation and preliminary validation of KIWEST using a large sample of Norwegian university staff. Scandinavian Journal of Public Health, 43(8), 855-866. https: / / doi.org/10.1177/1403494815600562

Ipsen C., Gish L., \& Poulsen S. (2015). Organizational-level interventions in small and medium-sized enterprises: Enabling and inhibiting factors in the PoWRS program. Safety Science, 71(Part C), 264-274. https:/ / doi.org/ 10.1016/j.ssci.2014.07.017

Kelloway K. E., Penney S. A. \& Dimoff J.(2017). Leading the Psychologically healthy workplace: The RIGHT way (pp. 113-128). In K. E. Kelloway, K. Nielsen, \& J. K. Dimoff, (Eds.), Leading to occupational health and safety. Chichester, UK: John Wiley \& Sons.

Kelloway E. K. D., \& Day A. L. (2005). Building healthy organizations: What we know so far. Canadian Journal of Behavioural Science, 37, 223-235. https:/ /doi.org/10.1037/ h0087259

Kuoppala J., Lamminpää A., Liira J., \& Vainio H. (2008). Leadership, job well-being, and health effects-A systematic review and a meta-analysis. Journal of Occupational and Environmental Medicine, 50(8), 904-915. https:/ / doi.org/ 10.1097/JOM.0b013e31817e918d

Listau K., Christensen M., \& Innstrand S. T. (2017). Work engagement - A double edged sword? A study of the relationship between work engagement and the workhome interaction using the ARK research platform. Scandinavian Journal of Work and Organizational Psychology, 2(1), 4. https://doi.org/10.16993/sjwop.20

Nielsen K. (2013). Review article: How can we make organizational interventions work? Employees and line managers as actively crafting interventions. Human Relations, 66(8), 1029 -1050. https:/ /doi.org/10.1177/ 0018726713477164

Nielsen K. (2017). Leaders can make or break an intervention - But are they villains of the piece? In E. K. Kelloway, K. Nielsen, \& J. Dimoff (Eds.), Leading to occupational health and safety: How leadership behaviors impact organizational safety and well-being (pp. 197-210). Chichester, UK: John Wiley \& Sons.

Nielsen K., \& Abildgaard J. S. (2013). Organizational interventions: A research-based framework for the evaluation of both process and effects. Work $\mathcal{E}$ Stress, 27(3), 278-297. https://doi.org/10.1080/02678373.2013.812358

Nielsen K., \& Daniels K. (2012). Enhancing team leaders' well-being states and challenge experiences during organizational change: A randomized, controlled study. Human Relations, 65(9), 1207-1231. https://doi.org/ $10.1177 / 0018726711433312$

Nielsen K., \& Miraglia M. (2017). Critical essay: What works for whom in which circumstances? On the need to move beyond the "what works?" question organizational intervention research. Human Relations, 70, 40-62. https:/ / doi.org/10-1177/0018726716670226

Nielsen K., Nielsen M. B., Ogbonnaya C., Känsälä M., Saari E., \& Isaksson K. (2017). Workplace resources to improve both employee well-being and performance: A systematic review and meta-analysis. Work \& Stress, 31, 101-120. https: / / doi.org/10.1080/02678373.2017.1304463

Nielsen K., \& Noblet A. (2018). Introduction organizational interventions: Where we are, where we go from here? In K. Nielsen \& A. Noblet (Eds.), Designing, implementing and evaluating organizational interventions (pp.1-23). London; UK: Routledge.

Nielsen K., \& Randall R. (2012). The importance of employee participation and perceptions of changes in procedures in a teamworking intervention. Work \& Stress, 26(2), 91-111. https:/ / doi.org/10.1080/02678373.2012.682721

Nielsen K., \& Randall R. (2013.) Opening the black box: A framework for evaluating organizational-level occupational health interventions. European Journal of Work and Organizational Psychology, 22(5), 601-617. https://doi. org/10.1080/1359432X.2012.690556

Nielsen K., Randall R., \& Christensen K. B. (2010). A longitudinal field study of the effects of team manager training. Human Relations, 63(11), 1719-1742. https://doi. org/10.1177/0018726710365004

Nielsen K., Randall R., Holten A.-L., \& Rial González E. (2010). Conducting organizational-level occupational health interventions: What works? Work E Stress, 24(3), 234-259. https: / / doi.org/10.1080/02678373. 2010.515393

Nytrø K., Saksvik P. Ø., Mikkelsen A., Bohle P., \& Quinlan M. (2000). An appraisal of key factors in the implementation of occupational stress interventions. Work E Stress, 14(3), 213-225. https:/ / doi.org/ 10.1080/02678370010024749

Richardson K. M., \& Rothstein H. R. (2008). Effects of occupational stress management intervention programs: A meta-analysis. Journal of Occupational Health Psychology, 13(1), 69-93. https://doi.org/10.1037/1076-8998.13.1.69

Saksvik P. Ø., Faergestad M., Fossum S., Indergård Ø., Olaniyan O. S., \& Karanika-Murray M. (2018). An effect evaluation of the psychosocial work environment of a university unit after a successfully implemented employeeship program. International Journal of Workplace Health Management, 11(1), 31-44. https:/ /doi.org/10.1108/ IJWHM-08-2017-0065

Saksvik P. Ø., Nytrø K., Dahl-Jørgensen C., \& Mikkelsen A. (2002). A process evaluation of individual and organizational occupational stress and health interventions, Work $\mathcal{E}$ Stress, 16(1), 37-57. https:/ / doi.org/10.1080/02678370110118744

Saksvik P. Ø., Olaniyan S. O., Lysklett K., Lien M. \& Bjerke L. (2015). A process evaluation of a salutogenic intervention. Scandinavian Psychologist, 2, e8. https:/ / doi. org/10.15714/scandpsychol.2.e8 
Schrøder M., Christensen M., Innstrand S. T., \& Fjeld A. (2017). Coworkership and prolific behaviors in modern work life. In M. Christensen, P. Ø. Saksvik, \& M. KaranikaMurray (Eds.), The positive side of occupational health psychology (pp. 99-114). Cham, Switzerland: Springer.

Skakon J., Nielsen K., Borg V., \& Guzmán J. (2010). Are leaders' well-being, behaviors and style associated with the affective well-being of their employees? A systematic review of three decades of research. Work \& Stress, 24(2), 107-139. https:/ / doi.org/10.1080/02678373.2010.495262

Sørensen O. H., \& Holman D. (2014). A participative intervention to improve employee well-being in knowledge work jobs: A mixed-methods evaluation study. Work \& Stress, 28(1), 67-86. https:/ /doi.org/10.1080/ 02678373.2013.876124

Westgaard R. H., \& Winkel J. (2011). Occupational musculoskeletal and mental health: Significance of rationalization and opportunities to create sustainable production systems - A systematic review. Applied Ergonomics, 42(2), 261-296. https:/ / doi.org/10.1016/ j.apergo.2010.07.002

Undebakke K. G., Innstrand S. T., Anthun K. S., \& Christensen M. (2014). ARK - Arbeidsmiljø- og klima undersøkelser, hvem - hva-hvordan. Rapportserie fra Senter for Helsefremmende Forskning [ARK-Work environment-and climate studies, who-what-how. Report series from the Center for Health Promotion Research] (NTNU 2014/04). Trondheim, Norway: Norges Teknisk-Naturvitenskapelige Universitet.

van den Heuvel M., Demerouti E., \& Bakker A. B. (2014). How psychological resources facilitate adaptation to organizational change. European Journal of Work and Organizational Psychology, 23(6), 847-858. https://doi.org/ $10.1080 / 1359432 X .2013 .817057$ 